\title{
The Mobile Phone in Africa: Has It Become a Highway to the Information Society or Not?
}

\author{
Elirea Bornman \\ University of South Africa, South Africa
}

\begin{abstract}
The single most dynamic ICT development in recent years has been the worldwide surge in mobile phone subscriptions. This "mobile miracle" has been continued in the developing world, particularly in Africa. At a time when discourses on the information society have focused on the internet, the mobile phone has been providing access to telecommunication to people at the bottom of the income pyramid - often for the first time in their lives. Moreover, mobile broadband internet has raised hopes that mobile phones will allow Africa to leapfrog across the digital divide towards becoming an information society. This article addresses issues related to Africa's position in the information society pertaining to access to mobile phones and mobile broadband; pricing, ICT skills and readiness, usage patterns, potential for usage in education, and impact on the lives of Africans. Conclusions are drawn on the potential role of mobile phones as information highways to the information society.
\end{abstract}

Keywords: Information society; Mobile broadband; Information highway; Mobile phone; Mobile technologies in education; Internet access in Africa

\section{Introduction}

Since the 1990s, particularly since academics and analysts have started to take note of the farreaching changes brought about by the explosive growth of information and communication technologies (ICTs), the concept of the "information society" has gained popularity (Van Audenhove, 2003). Although various definitions of an information society have been forwarded, the concept is generally associated with the proliferation of ICTs - the so-called "information highways" of our times - and beliefs that the new possibilities to create, store and distribute information via ICTs have ushered in a new kind of society, namely an information society.

In addition, it is widely believed that the proliferation of ICTs within a nation state or a society and the concomitant integration with the information society will have positive social and economic consequences as it will, among others, raise productivity, increase work opportunities, contribute towards the spread of information and knowledge, and in general foster development and raise the quality of life of the population (Van Audenhove, 2003). It is furthermore believed that the proliferation of ICTs could help developing countries to "leapfrog" stages of development towards becoming information societies (Hyde-Clark \& Van Tonder, 2011). Moreover, Manuel Castells $(2000,2001)$ holds that a society's economic growth and development is dependent on the spread of ICTs throughout the society. In contrast to this technophilic or optimistic view of the impact of ICTs there is, however, also a 
technophobic viewpoint which accuses technophiles of technological determinism. Van Dijk (1999) believes, for example, that ICTs could have wide-ranging negative effects for a society as it can lead to a decrease in work opportunities and increase the gap between the rich and the poor.

Concomitant with the technophobic view of the impact of ICTs are discourses on the "digital divide" (Madikiza \& Bornman, 2007). It is believed that disparities between developed and developing countries with regard to access to and control of information highways hamper attempts by developing countries to compete in the global economy and on other terrains and become full players in the information society. Technophiles nevertheless believe that the spread, uptake and use of ICTs remain the only way to bridge the digital divide.

The digital divide and its dire consequences are at its most conspicuous on the African continent and, in particular, in Sub-Saharan Africa. Africa is by far the least computerized region of the world (Castells, 2000; Jensen, 2006). With the exception of a few major cities, ICT infrastructure on the continent is scarce at best and nonexistent at worst (Kamalipour, 2007). African countries also rank relatively low - below the top 50 - in most indices of globalization and the information society (Dutta \& Mia, 2009; International Telecommunication Union [ITU], 2011). In an era where other developing countries such as those in East-Asia have been making major strides towards becoming modern economies and full members of the information society, Africa and Sub-Saharan Africa are experiencing a noteworthy deterioration in their relative position with regard to trade, investment, production and consumption. Castells (2000) ascribes this state of affairs predominantly to the region's social exclusion from the information highways of our world.

Thus the question can be posed: What does Africa - and Sub-Saharan Africa in particular need to do to change its exclusion from the information society? Can the mobile phone play a role in helping the continent to leapfrog the digital divide? These and other questions will be addressed in the sections that follow.

\section{Conceptualization of and Processes towards Becoming an Information Society}

Webster (2006) remarks that it seems so obvious to many analysts that we live in an information society, that they often blithely assume that it is unnecessary to define the concept. It is however important to ask how information is assuming a more central role in today's world and what kind of changes are associated with the more central role that information plays in our daily lives.

Webster (2006) distinguishes five definitions of the information society. Although they are not mutually exclusive, each focuses on various factors and processes that are ushering in a new kind of social system - the information society. The most well-known of these definitions is the technological definition which emphasizes the role of an array of technological developments, and in particular newly developed ICTs, that have been creating a new kind of society. Castells $(2000,2001)$ regards the proliferation of ICTs, and the ability to adapt to and make use of the opportunities created by ICTs, as the critical factor determining a society's membership of the information society. Technological infrastructure, which includes advanced telecommunication networks, internet connectivity, the infrastructure to make use of computers and advanced computer systems (including electrification), is a vital factor in this regard. 
The spatial definition views the information society in terms of information networks that connect various locations (Webster, 2006). Castells $(2000,2001)$ prefers to use the term "network society" in this regard. In the network society, according to Castells, spatial and time restraints are no longer relevant. The economic definition, on the other hand, focuses on the economic changes associated with the greater availability of information. It considers an increase in the gross national product (GNP) that can be accounted for by information as an indication of a country being an information society or not. According to Castells (2000), the information networks created by ICTs have furthermore given rise to a new economic system global informational capitalism - in which information has become a key commodity.

According to the occupational definition, an information society is characterized by the preponderance of occupations associated with information work, such as lecturers, librarians, researchers, and so forth (Webster, 2006). This viewpoint coincides with Castells' (2001) emphasis on the proportion of knowledgeable labor in a country. According to Castells, selfprogrammable labor refers to those people that can become producers of knowledge and information, that is, people with high educational qualifications and exceptional skills levels. Non-self-programmable or generic labor, on the other hand, refers to people who do not have the capacity to generate productivity in a similar way than self-programmable labor. The most important factor that distinguishes the two groups is not only education but also the quality of education. Thus it is not only information infrastructure, but also the quality of the educational systems of a country and the proportion of the population that achieves high levels of education that determine a country's inclusion in or exclusion from the information society and the informational economy.

The fifth definition of Webster (2006) emphasizes the cultural implications of living in an information society. The information society is viewed as a media-laden society where the informational features are thoroughly pervasive and the informational environment more intimate and more constitutive of who and what we are than ever before.

The ITU (2011) identifies a three-stage model that countries or regions follow in becoming an information society. The three stages are the following:

- The first phase represents network-readiness as reflected by the proliferation of networked ICT infrastructure within a society or country and the degree of access that individuals, businesses, and institutions have to this infrastructure. Thus the emphasis falls on access to ICTs. This phase closely coincides with Castells' (2000) notion of the proliferation of ICT infrastructure within a region or society.

- The second level involves ICT intensity, namely the degree of uptake and use of ICTs by individuals and other role-players within a society. The ITU (2011) mentions in this regard the ICT and other skills of a population that enable the effective use of ICTs. This phase coincides with Castells' (2001) notion of "knowledgeable labor" as a distinctive feature of an information society.

- The third and final stage represents the actual impact of the effective use of ICTs in a particular society or region. The ITU (2011) maintains that reaching the final stage, thus becoming an information society and a competitive role-player in the information economy, depends on the first two stages. 
According to the ITU (2011), no participation in the information society is possible in the absence of information highways as represented by networked ICT infrastructure. A society can also not reap the advantages of becoming an information society without a large percentage of people who have both the skills and the knowledge to use ICTs maximally. Thus economic growth and development will remain below potential and a country or region will remain socially excluded from the information society if it does not meet both criteria.

Although the second stage does refer to human elements, the ITU's (2011) approach is predominantly technological deterministic in nature (Van Dijk, 1999). It furthermore holds an overly simplistic viewpoint of the advancement of societies towards modern information societies and competitive participation in the global informational economy. The complex interplay between cultural, social, political and economic factors that play a role in determining the status and economic situation of countries is largely ignored. The viewpoints of the ITU (2011) nevertheless largely coincide with other attempts to measure the global interconnectedness of countries, such as the Network Readiness Index (NRI) of the World Economic Forum (Dutta \& Mia, 2009). It also provides a useful framework for the study and analysis of the proliferation and impact of particular technologies in particular societies. In this aerticle it will be used to analyze the spread and impact of the mobile phone in Africa.

\section{The Position of Africa in the Information Society}

As already indicated, Africa is by far the least computerized region in the world (Castells, 2000; Jensen, 2006). In the first instance, Africa often lacks the minimum infrastructure required for using computers, such as electrification. Where electricity supplies are nonexistent or unreliable, efforts to supply electronic equipment to a country or region become futile. The critical aspect is, however, networking capability to link to the internet and other global communication networks. Networking capability requires telecommunications infrastructure and network connectivity. However, many schools, universities and research centers on the African continent have no internet access at all. Where basic ICT infrastructure does exist, networks are mostly meager and fragile in comparison with world standards. The consequence is that, although $14.1 \%$ of the world's population live in Africa, Africa houses only $2.1 \%$ of the internet users in the world (Hyde-Clark \& Van Tonder, 2011). Furthermore, in South Africa one of the most connected countries in Sub-Saharan Africa - only $15 \%$ of households have a working computer and only $5 \%$ of households have internet access. In addition, Sub-Saharan Africa has the lowest teledensity in the world and a large unmet demand for telecommunication services. It is not only a problem of basic connectivity, but also of bandwidth. The reality is that even Africa's most well-equipped centers of excellence have less bandwidth than a home broadband user in Europe and North America (Jensen, 2006). The most important reason is the low penetration of fiber-optic cables that have a vast capability of transferring data (Song, 2005). North Africa is however in a better position than the rest of Africa as it has access to a web of cables criss-crossing the Mediterranean.

It can be assumed that the above-mentioned problems would have an adverse impact on ICT subscriptions and ICT usage in Africa. This assumption is indeed confirmed by the ITU (2011) which indicates that 80 percent of people living in developing countries - of which the largest percentage live in Africa - do not have internet access yet and even fewer have access to broadband internet. Household subscriptions, especially, remain disconcertingly low. The only exceptions are Tunisia and Nigeria where it can be said that approximately one third of the population use the internet. Interestingly, Kenya - who is identified by the ITU (2011) as one of 
the African countries that has made major strides in recent years - has overtaken South Africa in terms of the number of internet users per 100 of the population. This tendency stands in contrast to some positive developments in Africa such as the laying of additional fiber-optic cables that link the continent with the rest of the world (Song, 2005). While infrastructure development is currently the key driver of ICT growth on the continent, a number of other factors, such as cost structures and ICT skills - as discussed in the following sections - are hindering ICT usage on the continent. In fact, the ITU (2011) concludes that Africa has made more progress in recent years in terms of infrastructure development than in terms of the actual uptake and use of ICTs. It thus appears that the continent is still in a very early stage of becoming an information society.

Whereas discussions on the position of Africa in the information society have been dominated by discourses on internet access, the single most dynamic development with regard to ICT access and use in recent years has been the worldwide surge in mobile phone subscriptions. While fixed-line telecommunication has been declining all over the world, the worldwide growth in mobile-cellular technology is depicted by the ITU (2011) as a "mobile miracle". In fact, the mobile-cellular market has become the fastest growing telecommunications industry in history. By the end of 2010 there were, for example, 5.3 billion mobile phone subscriptions worldwide, in comparison with 4 billion in 2004. Whereas the growth in mobile telephony has now reached a point of saturation with penetration rates of over a 100 percent in the developed world, the "mobile miracle" has been continued in the developing world with spectacular growth rates of over 20 percent per annum. With the advent of mobile broadband internet, the question arises whether the mobile phone can play a significant role in promoting growth and development in Africa and in integrating the continent with the information society.

\section{The Proliferation of Mobile Phones, Mobile Internet, and ICT Skills in Africa}

In the developed world, the mobile phone represents an extension of pre-existing fixed-line telephony (Ling \& Horst, 2011). However, people in the developing world have only had limited access to telecommunications - often only by means of payphones. As recently as 2000 subscription rates to fixed-line networks in Africa were as low as 3 percent (Bailard, 2009). It was initially believed that the lack of interest in fixed-line telephony - whether due to financial limitations or other reasons - would apply to mobile phones also. Thus the possibilities of the African market have been overlooked by most. However, despite the fact that fixed-line subscriptions have continued to stagnate at less than 4 percent, mobile phone penetration rates soared from lower than 2 percent in 2000 to above 90 percent in a number of African countries (Calandro, Gillwald, Moyo, \& Stork, 2010). Thus the mobile phone has quietly come to provide access to electronically mediated communication to people at the bottom of the income pyramid - often for the first time in their lives.

\section{Access to Mobile Telephony in Africa}

The tremendous growth in the uptake of mobile telephony is particularly noteworthy for African and Sub-Saharan countries (see Table 1 - Calandro et al., 2010). 
Table 1. Mobile Cards Sold as a Percentage of the Population (adapted from Calandro et al., 2010)

\begin{tabular}{|l|r|r|r|r|}
\hline Countries & $\mathbf{2 0 0 6}$ & $\mathbf{2 0 0 7}$ & $\mathbf{2 0 0 8}$ & $\mathbf{2 0 0 9}$ \\
\hline Botswana & 44.10 & 60.86 & $\mathbf{7 7 . 3 4}$ & 96.12 \\
\hline Tunisia & 73.60 & 77.89 & 84.59 & 94.96 \\
\hline South Africa & 81.54 & 86.02 & 90.60 & 92.67 \\
\hline Ghana & 23.30 & 33.25 & 49.55 & 63.38 \\
\hline Cote d'Ivoire & 20.70 & 37.11 & 50.74 & 63.33 \\
\hline Benin & 13.00 & 24.45 & 41.85 & 56.33 \\
\hline Namibia & 29.73 & 38.31 & 49.39 & 56.05 \\
\hline Senegal & 25.75 & 30.53 & 44.13 & 55.06 \\
\hline Kenya & 19.96 & 30.06 & 42.06 & 48.65 \\
\hline Nigeria & 22.40 & 27.35 & 41.66 & 47.24 \\
\hline Tanzania & 14.37 & 20.16 & 30.62 & 39.94 \\
\hline Cameroon & 17.20 & 24.31 & 32.28 & 37.89 \\
\hline Zambia & 13.84 & 21.43 & 28.04 & 34.07 \\
\hline Uganda & 6.77 & 13.69 & 27.02 & 28.69 \\
\hline Mozambique & 11.00 & 14.08 & 19.68 & 26.08 \\
\hline Rwanda & 3.41 & 6.72 & 13.61 & 24.30 \\
\hline Burkina Faso & 7.10 & 10.94 & 16.76 & 20.94 \\
\hline Ethiopia & 1.10 & 1.54 & 2.42 & 4.89 \\
\hline
\end{tabular}

Calandro et al. (2010) warn that the data reported in Table 1 could represent an overcalculation (even by millions) of penetration rates as most markets are characterized by multiSIM usage. However, even when taking possible over-counting into account, there has been a rapid growth in the uptake of mobile services as indicated by vast differences between the figures for 2006 and 2009. Whereas South Africa and Tunisia maintained a leadership position between 2006 and 2008, they were overtaken by Botswana in 2009 as the African country with the highest mobile penetration. In Botswana, Tunisia and South Africa, mobile penetration has nearly reached a saturated rate of 100 percent - similar to many developed countries. Cote d'Ivoire, Ghana and Senegal have also seen tremendous growth rates. Even countries at the bottom of the index such as Burkina Faso and Rwanda have experienced significant growth rates - albeit from low baselines. However, in a large number of African countries mobile penetration is still below 50 percent and in a country such as Ethiopia as low as 4.89 percent.

The conclusion can be drawn that the lack of fixed-line subscriptions in Africa cannot be ascribed to a lack of interest in telephony and the concomitant access to the information society (Bailard, 2009). The real reasons for the lack of demand for fixed-line services are the relatively high cost of fixed-line infrastructure, the fact that it has not been available in many rural areas, and a variety of other factors. In contrast, due to the privatization of telecommunication industries since the mid-1990s, most mobile phone markets are characterized by competitive industries due to the presence of more than one operator (Bailard, 2009; ITU, 2011). The result is more affordable and reliable mobile services. People also do not have to wait for long periods of time to have a mobile phone installed. They can nowadays buy it over the counter from a multitude of dealers. The advent of pre-paid or "payas you-go" (or rather "pay-as-you-use") services have furthermore helped poorer users to control telecommunications costs. 


\section{Mobile Broadband in Africa}

The impact of the mobile phone is however not restricted to basic telecommunication services. Wireless broadband access via mobile technology has also become a significant growth sector and the growth in mobile broadband subscriptions has been the single most dynamic aspect of the ICT sector in the past years (ITU, 2011). Even in developed countries people are shifting increasingly to wireless broadband access via devices such as mobile phones and tablets. In developing countries the mobile revolution - which includes access to wireless internet via mobile phones - holds the promise of bringing people online and being a key enabler in helping countries to leapfrog stages of development and to experience the many benefits of the information society (Castells, 2000, 2001; ITU, 2011).

However, despite these promising developments, more than 70 percent of the world's population - and more than 80 percent of people living in developing countries - do not have internet access yet and even fewer have access to broadband internet (ITU, 2011). In many developing countries, therefore, schools, hospitals, other institutions and households located outside major urban centers do not have access to high-speed internet services. Table 2 gives an overview of access to mobile broadband as well as general internet access in a number of African countries (Calandro et al., 2010).

Despite the spectacular growth in mobile access, the data in Table 2 indicate that access to wireless internet via mobile phones has remained limited notwithstanding the fact that most mobile operators in Africa have introduced broadband services, including $3 \mathrm{G}$ and $3.5 \mathrm{G}$ (Calandro et al., 2010). It is only in South Africa, one of the first countries to introduce mobile broadband services, where ADSL connections have been overtaken by mobile internet subscriptions. However, it is not only the case that mobile internet subscriptions have been low. The low levels of subscription to mobile broadband services are merely another reflection of the overall low levels of internet subscription, internet access and internet use in African countries.

Table 2. Internet Access for a Number of African Countries in 2009 (adapted from Calandro et al., 2010)

\begin{tabular}{|l|r|r|r|r|}
\hline \multicolumn{5}{|c|}{ Statistics Reported per 100 of the Population } \\
\hline Countries & $\begin{array}{r}\text { Internet } \\
\text { Subscriptions }\end{array}$ & $\begin{array}{r}\text { Internet } \\
\text { Users }\end{array}$ & $\begin{array}{r}\text { Fixed Broadband } \\
\text { Internet } \\
\text { Subscriptions }\end{array}$ & $\begin{array}{r}\text { Mobile cellular } \\
\text { Internet } \\
\text { Subscriptions }\end{array}$ \\
\hline Tunisia & 4.03 & 34.07 & 3.63 & 10.52 \\
\hline South Africa & Not available & 8.82 & 0.96 & 2.97 \\
\hline Botswana & Not available & 6.15 & 0.77 & 0.24 \\
\hline Senegal & 0.47 & 7.36 & 0.47 & 0.15 \\
\hline Ghana & 0.38 & 5.44 & 0.11 & 0.03 \\
\hline Rwanda & 1.47 & 4.50 & 0.08 & 0.40 \\
\hline Zambia & Not available & 6.31 & 0.06 & 4.89 \\
\hline Mozambique & 0.059 & 2.68 & 0.05 & \\
\hline Nigeria & 0.58 & 28.43 & 0.05 & 0.05 \\
\hline Cote d'Ivoire & Not available & 4.59 & & \\
\hline
\end{tabular}




\begin{tabular}{|l|r|r|r|r|}
\hline Burkina Faso & Not available & 1.13 & 0.04 & \\
\hline Kenya & 2.11 & 10.04 & 0.02 & 4.98 \\
\hline Benin & 0.21 & 2.24 & 0.02 & 1.48 \\
\hline Namibia & Not available & 5.87 & 0.02 & 1.10 \\
\hline Uganda & 0.91 & 9.78 & 0.02 & 1.37 \\
\hline Tanzania & Not available & 1.55 & 0.02 & 0.49 \\
\hline Cameroon & 0.13 & 3.84 & 0.00 & 0.10 \\
\hline Ethiopia & 0.58 & 0.54 & 3.498 & \\
\hline
\end{tabular}

The low levels of internet access in most African countries are confirmed by the ITU (2011). Only three African countries ranked among the top 100 countries with regard to their composite measure (IDI index) for ICT access and use: Mauritius (69), the Seychelles (71) and South Africa (97). Furthermore, the IDI values for these three countries vary between 3 and 4 in comparison with the 8 of the Republic of Korea at the top of the list.

\section{Pricing Structures in Africa}

It is, however, not only the availability of infrastructure that determines its use, but also price structures (ITU, 2011). The price of a mobile phone call, an SMS or a mobile broadband connection will determine how many people will subscribe to a particular service and how often and for what purposes they will use it. The period from 2008 to 2010 has not only been characterized by a tremendous growth in mobile phone subscriptions, but also by a 21.8 percent drop in prices of mobile services worldwide. This drop in prices was however higher in developed than in developing countries.

The prices of ICT services have nevertheless remained high in most African countries in comparison with the rest of the world. In a comparison of the overall price basket for ICT services, only six African countries fall under the 100 cheapest countries: Mauritius (47); Tunisia (65); Algeria (71); Egypt (78); Botswana (85) and South Africa (99). The results furthermore confirm that countries with relatively high ICT prices have relative low ICT access and use.

Similar to the overall drop in prices for ICT services, the prices for a basket of mobile services (30 outgoing calls and 100 SMSs) also dropped worldwide by 21.8 percent (ITU, 2011). However, the ten countries with the highest prices for a basket of mobile services are all in Africa: Malawi, Niger, Zimbabwe, Togo, Burkina Faso, Mozambique, Madagascar and Chad. The only light in this tunnel is the fact that the five countries mentioned last had also seen the largest decrease in prices in the last two years in absolute terms. Similar to the price structures for ICT services in general, only six African countries ranked among the 100 cheapest countries in the world with regard to the mobile price basket: Mauritius (37); Botswana (67); Tunisia (82); Algeria (86); Tonga (93) and Egypt (96). Thus, although there are positive indications that the prices of mobile services are coming down, the overall price structures for mobile services remain high. 


\section{ICT Skills and the Readiness of the Population to use ICTs}

Whereas data on ICT penetration rates, and particularly those for mobile subscriptions, are more readily available from household surveys and service providers, it is much more difficult to obtain data for and to compare levels of education and ICT skills. Research by the ITU (2011) nevertheless emphasizes the importance of these variables. The ITU found that internet usage tends to be much higher among people with higher levels of education. Higher levels of education also correlated with a higher income and a higher degree of computer literacy both important factors that determine people's internet subscriptions as well as internet usage.

The relationship between income and internet usage is furthermore much stronger for Africa than for the developed world (ITU, 2011). Whereas hardly any Africans with only primary education were using the internet, large percentages of Africans with tertiary qualifications were online. There were however noteworthy differences between countries regarding internet access among the highly educated, ranging from 90 percent in Rwanda to less than 20 percent in Uganda. In most African countries a strong relationship was also found between income and internet access. In Botswana, for example, only 2 percent of people in the lowest three income quartiles accessed the internet. In contrast, the concomitant figure for the highest income quartile was 19 percent. Interestingly, the relationships between education levels and internet access are much less conspicuous for developed countries. One of the reasons might be that internet subscription is much cheaper in the developed than in the developing world. In Africa it appears, however, that internet access remains the preserve of the highly educated and wealthy elite, namely those who can afford internet subscription and those who have the necessary skills to use it. Thus a digital divide also exists within African countries - between the wealthy educated and the poor uneducated.

The ITU (2011) nevertheless voices the opinion that the advent of mobile internet will not only alleviate problems with ICT infrastructure, but will also play an important role in enhancing ICT skills in Africa. The skills for using a mobile phone are relatively simple. The fact that many Africans are already using mobile phones implies that they have already mastered some basic ICT skills which could make it easier for them to go online. Furthermore, the availability of prepaid mobile broadband could serve to lower the income barrier and allow low-income customers to buy small amounts of data volumes to access the internet whenever they have money available. Electricity also poses less of a barrier as minimal facilities are needed to load a mobile phone battery. Thus it appears that the mobile phone is already serving and could in future serve to be the first step for many Africans to access the information society.

\section{Usage of Mobile Phones in Africa}

The impact of mobile phones on development will, however, in the end be determined not only by the number of owners of SIM cards and subscription rates, but also by the actual ways in which mobile phones are used and the benefits that Africans derive from using mobile phones (ITU, 2011; James \& Versteeg, 2007).

The proliferation of mobile phones in Africa has already had a vast influence on micro, meso and macro contexts. Mobile phones have in the first place been enhancing friendships and family interaction and have resulted in the tightening of social cohesion among close friends and family members (Ling \& Horst, 2011). It has however been found that mobile phones do 
not expand social networks - as is often the case with internet platforms such as Facebook and Twitter - but rather serve to intensify existing social networks. Ample evidence furthermore exists of the use of mobile phones for business and governance purposes and the ways that it is changing daily life in Africa (Bailard, 2009). For example, buyers and sellers can connect more readily creating more efficient markets in the process; small business owners and vendors are less dependent on middlemen, thus reducing their susceptibility to extortion and bad information; mobile banking has given poor people access to basic banking services, made payments easier and simplified the payment of remittances; while access to government services, e-education and e-health services have been streamlined. According to Isaacs (2012), examples such as these point to the fact that the mobile phone has become ubiquitous and suggest the "mobilization" of African society.

James and Versteeg (2007) suggest, however, that both the quality and quantity of mobile phone usage will be lower in developing countries. The lower levels of mobile penetration imply that people in developing regions will use mobile phones less frequently. However, James and Versteeg warn that the fact that many Africans do not subscribe to mobile telephony does not mean that they do not make use of mobile telephony. Sharing of mobile phones is a common practice in Africa. In Tanzania there is, for example, at least one additional user for each owner of a mobile phone. However, people sharing a mobile phone will often buy their own SIM card which will be reflected in SIM card data. Facilities for commercial sharing, namely mobile services that are available after payment, are also widespread in Africa (Sey, 2007). It can nevertheless be assumed that people who share a mobile phone with other people or make use of commercial services will use the phone less than owners of phones. Household surveys in Tanzania and South Africa indicate, for example, that approximately 76 percent of mobile owners use their phones four times or more per week (James \& Versteeg, 2007), while only 24 percent in South Africa and 16 percent in Tanzania of non-owning users use a phone four times per week or more. It is furthermore assumed that users in developing countries make shorter calls than in developed countries. Owning users also make longer calls than non-owning users. These tendencies are furthermore aggravated by the relative higher prices of mobile services in Africa (ITU, 2011).

It is moreover expected, as already mentioned, that the quality of mobile usage will also be lower in developing countries (James \& Versteeg, 2007). In developed countries mobile phones have been developing in multimedia devices used for receiving and sending e-mails, photographs and real-time exchange of information. The reality is probably very different in developing countries where the costs of services are much higher. Methods of saving costs such as "beeping signals" (to notify a recipient to call back) and cost-effective ways of texting, such as MXit in South Africa, have been developed. According to Gillwald (2005), African users have been using multiple communication strategies in which they use whatever medium is available in different ways, depending on two key factors, namely convenience and disposable income. Depending on the circumstances, they will make alternative use of public access phones, mobile phones, mobile phone kiosks and traditional landlines. It is, for example, unlikely that they will make a mobile phone call costing about 30 US cents in the middle of the month. In such a case it is more likely that a limited amount of airtime will be bought from a mobile kiosk.

In addition, different types of usage are characterized by various levels of quality and complexity (Hyde-Clark \& Van Tonder, 2011; James \& Versteeg, 2007). If somebody borrows, for example, a mobile phone to make a call or uses a mobile phone kiosk, it means that this person can make a call, but cannot receive a call at any time. The research by Hyde-Clark and 
Van Tonder (2011) furthermore indicates that the activities performed via mobile internet are also qualitatively different from those performed via computer-based broadband access. A sample of youth in the Johannesburg area indicated that they use broadband access via their mobile phones primarily to check their e-mail and to interact with friends on Facebook and other social networks. However, a third of the respondents did not believe that mobile phones can replace computers. The reasons were, inter alia, the limited storage and memory capacity of mobile phones; the fact that more complex functions can be performed on computers; the fact that it is more convenient to browse the internet via a computer; the possibility to play more complex games and the option to use several programs at the same time. One of the respondents commented: "A computer has an ability of its own. It's more sophisticated, smarter and has better functions and a wide variety of programs. Some functions just can't be replaced by a phone, for instance Microsoft Word, Excel, PowerPoint, et cetera" (Hyde-Clark \& Van Tonder, 2011, p.271).

More complex functions are however available on newly developed smart phones and iPhones which are web-friendly and multi-media-friendly as well as other mobile devices such as iPads (Isaacs, 2012). However, cost remains a critical factor and indications are that few people in Africa own technologically advanced mobile phones. Hyde-Clark and Van Tonder (2011) conclude that the mobile phone is predominantly used in Africa for voice communication, SMSs and limited access to and use of social networks. Overall, the mobile phone unfortunately does not (yet) replace the complexity of functions offered by broadband access via a computer.

\section{Usage of Mobile Phones in Education}

As already indicated, future development of the African continent - and in particular its development towards an information society - will depend largely on its ability to provide quality education to all citizens (Caste \& Isaacs, 2007; ITU, 2011). However, in the last two decades Africa has been experiencing a continuing debilitating crisis in education associated with low levels of access to educational opportunities, a shortage of highly qualified teachers and a lack of basic literacy skills among large sections of the population (Isaacs, 2012). Various attempts to address these challenges have only been marginally successful. Both governments and educators have consequently been placing their hopes on ICTs to address these and other problems, to enhance the quality of education and to provide education to those formerly excluded from educational opportunities. Whilst the dominant ICT access model in schools has been computer labs, the rapid growth in mobile penetration has been creating new opportunities - and new hopes - for addressing the systemic challenges related to education and to positively transform the scope, scale and quality of education in the region (Farrell \& Isaacs, 2007).

The term m-learning has evolved in this regard (Koszalka \& Ntloedibe-Kuswani, 2010). Mlearning differs from e-learning in the sense that mobile technologies are employed to support education for learners who are mobile themselves. Instructional activities are not limited to a set place such as a computer lab, but can be conducted anywhere and anytime - within and outside the walls of formal classrooms - where learners can engage, often asynchronously, with teachers, learning resources and other learners.

A plethora of m-learning initiatives related to all levels of education have emerged (Isaacs, 2012). The Wireless Mothers project in Zanzibar and Tanzania aims to provide information to 
mothers regarding childbirth and the prevention of child mortality. The Cocoa Link project of the Ghana Cocoa Board employs mobile phones to provide information on cocoa farming practices to farmers. The BridgelT project in Tanzania provides digital video content for ondemand screening in classrooms via mobile phones. The Dr Math on MXit project in South Africa gives learners access, via mobile phones, to a range of learning resources as well as tutor help in mathematics (Koszalka \& Ntloedibe-Kuswani, 2010). Research indicated that tutors helped more than 50 students per hour. Mobile phones have furthermore been used by the University of Pretoria and the University of South Africa as a communication channel with distance education students. Research at the University of Pretoria indicated that $96 \%$ of the distance education students had access to mobile phones, while only $1 \%$ had access to the internet at home. In a comparative project with the USA, video-enabled mobile phones were given to the parents of three- and four year olds in Tanzania. Approximately half of the families lived above and half below the poverty line. Video clips were used to teach the children the alphabet. Research demonstrated that the majority of children improved their knowledge of the alphabet. This effect was furthermore more pronounced in the case of poorer families.

These projects are all based on beliefs in the benefits that mobile phones hold for education. Firstly, not only the affordability of mobile phones and high levels of access, but also their special characteristics - the relatively small size, portability and advanced features such as voice, display, the potential for internet access and interactivity - are important reasons for the interest in employing mobile phones in education (Koszalka \& Ntloedibe-Kuswani, 2010). In particular, the potential for interactivity provides opportunities for collaborative learning among distance learners (Makoe, 2010). As reflected in some of the projects discussed above, the mobile phone is also perceived to hold the potential for opening up new ways for informal, personalized and situated learning (Isaacs, 2012). It furthermore holds the opportunity for extending the reach of education to remote areas.

However, the use of mobile phones has also met with resistance, criticism and obstacles (Koszalka \& Ntloedibe-Kuswani, 2010). Firstly, text-based material - as is usually employed when using mobile phones - is not suitable for illiterate people or preschool children. Although smart phones offer advanced services such as interactive voice response (IVR), access to smart phones - as already mentioned - is limited (Adam, Butcher, Tusubira, \& Sibthorpe, 2011; Isaacs, 2012). Discussions on usage of mobile phones in education are furthermore often confounded with other wireless devices such as iPads and Kindles to which Africans still have limited access (Isaacs, 2012). Besides, many educators do not allow mobile phones into classrooms as they believe that the phones distract the attention of learners and disrupt learning. Usability challenges such as the small screen size also exist. Continuing fragmentation in the mobile industry represents a further challenge for the scalability and sustainability of educational efforts. Educational material needs to be developed and/or adapted for a variety of hardware and systems which often have different capabilities even under the same system. In addition, the co-operation of national regulators as well as a strong business model is often a prerequisite to ensure the participation of all service providers.

In spite of the significant growth of SIM-ownership, as previously discussed, the full use of the mobile phone in education is still hampered by issues of access and costs, especially in poorer African countries (Adam et al., 2011). Educational efforts aimed at women are furthermore negatively influenced by a gender gap. Research indicates that an African man is $23 \%$ more likely to own a mobile phone than a woman (Cherie Blair Foundation, 2010). Another stumbling block is the lack of enabling policy environments - not only regarding educational policies, but also related policies such as regulatory policies, policies regarding infrastructure 
development, and so forth. In addition, Isaacs (2012) points out that attempts to employ the mobile phone in education follow years of successive waves of efforts to make newly developed technologies work in resource-poor environments. These efforts are often highly techno-centric in nature and often entail the mere layering of new technologies on top of others, while the broader complex interplay of factors plaguing education in Africa is ignored.

Although anecdotal evidence does point to the fact that mobile phones could potentially have many benefits for education in Africa, most analysts are of the opinion that too little is currently known (Isaacs, 2012). Most of the current projects are limited in nature and research is still in its infancy, as few examples of rigorous research exist (Koszalka \& Ntloedibe-Kuswani, 2010). Many studies have weak research designs, sampling issues exist and a strong and strategically established research agenda is still lacking.

\section{The Impact of the Mobile Phone in Africa}

According to the ITU (2011), the final stage in becoming an information society entails reaping the benefits and implications of increased access and use of ICTs. The final issue that therefore needs to be considered is whether and to what extent the mobile phone fosters growth, development and the improvement of education on the African continent and whether it can become a key factor in helping the continent to leapfrog stages of development towards becoming an information society.

As already mentioned, ample evidence exists that the mobile phone fosters wide-ranging changes in the lives of African people (Bailard, 2009). Research has indeed showed that mobile phones are contributing towards the reduction of price discrepancies; lead to increasing consumer and producer welfare; facilitate improved productivity; assist people in finding employment; reduce corruption on the continent; and enhance education on various levels. However, the most recent data of the ITU (2011) indicate that most African countries are still ranked low on most indices of the information society. It can therefore be concluded that the mobile phone has not (yet) succeeded in bridging the digital divide between Africa and the rest of the world (Hyde-Clark \& Van Tonder, 2011).

The most important reason is most probably that internet access via mobile phones cannot replace broadband access via computers. Although smart phones and other wireless devices do offer more complex functions, the proliferation of these devices is still limited in Africa (Isaacs, 2012). It is therefore not only a question of access to and use of ICTs. Ultimately, it is the complexity of functions offered by particular devices that makes all the difference. As mobile phones cannot offer the full range of complex functions offered by broadband internet via computers (yet), it is doubtful whether they can serve as a short cut to the information society. Making use of complex devices furthermore requires a highly educated population that has developed advanced ICT skills and the existence of a relatively high percentage of knowledgeable labor within a society.

There is consequently no shortcut for Africa to becoming an information society. Bridging the digital divide between Africa and the rest of the world (still) requires the roll-out of the infrastructure for the use of computers (e.g. electrification) and for fixed-line broadband access (fiber-optic cables); the broadening of access to mobile broadband; the implementation of policies to bring costs even further down in order to be at least in line with the rest of the world; the advancement of ICT critical skills beyond the use of mobile phones; and - most 
importantly - a holistic approach towards advancing the quality of education in which technology is used in innovative ways, but the broader interplay of factors impinging on education are simultaneously addressed.

\section{References}

Adam, L., Butcher, N., Tusubira, F. F., \& Sibthorpe, C. (2011). Transformation-ready: The strategic application of information and communication technology in Africa. Paris: Unesco.

Bailard, C. S. (2009). Mobile phone diffusion and corruption in Africa. Political Communication, 26, 333-353.

Calandro, E., Gillwald, A., Moyo, M., \& Stork, C. (2010). Comparative ICT sector performance review 2009/2010. Cape Town: Research ICT Africa.

Castells, M. (2000). End of millennium: The information age: Economy, society and cultureVolume III (2nd ed.). Oxford: Blackwell.

Castells, M. (2001). The new global economy. In: J. Muller, N. Cloete \& S. Badat (Eds.), Challenges of globalization: South African debates with Manuel Castells (pp. 2-21). Johannesburg: Maskew Miller Longman.

Cherie Blair Foundation (2010). Women and mobile: A global opportunity - A study on the mobile phone gender gap in low and middle income countries. Retrieved on 12 October 2012 from http://www.cherieblairfoundation.org/uploads/pdf/women_and_mobile_ a_global_opportunity.pdf

Dutta, S. \& Mia, I. (Eds.). (2009). The global information technology report 2008-2009. Geneva: World Economic Forum.

Farrell, G. \& Isaacs, S. (2007). Survey of ICT and education in Africa: A summary report, based on 53 country survey. Washington, DC: InfoDev/World Bank.

Gillwald, A. (Ed.). (2005). Towards an African e-index: Household and individual ICT access and usage across 10 countries in Africa. Johannesburg: The Link Centre, University of the Witwatersrand.

Hyde-Clark, N. \& Van Tonder, T. (2011). Revisiting the "leapfrog" debate in light of current trends of mobile phone Internet usage in the Greater Johannesburg area, South Africa. Journal of African Media Studies, 3(2), 263-276.

International Telecommunication Union (ITU). (2011). Measuring the information society: 2011. Geneva: ITU.

Isaacs, S. (2012). Turning on mobile learning in Africa and the Middle East: Illustrative initiatives and policy implications. Paris: Unesco.

James, J. \& Versteeg, M. (2007). Mobile phones in Africa: How much do we really know? Social Indicators Research, 84, 117-126.

Jensen, M. (2006). Lowering the costs of international bandwidth in Africa (draft format). [0]. Retrieved on 23 September 2010 from http://rights.apc.org/documents/fibre_ bandwidth_EN.pdf 
Kamalipour, Y.R. (Ed.). (2007). Global communication (2nd ed.). Belmont, CA: Thomson Wadsworth.

Koszalka, T.A. \& Ntloedibe-Kuswani, G.S. (2010). Literature on the safe and disruptive learning of mobile technologies. Distance Education, 3(2), 139-157.

Ling, R. \& Horst, H.A. (2011). Mobile communication in the global south. New Media \& Society, 13(3), 363-374.

Madikiza, L. \& Bornman, E. (2007). International communication: Shifting paradigms, theories and foci of interest. Communication, 30(2), 11-44.

Makoe, M. (2010). Exploring the use of MXit: A cell-phone social network to facilitate learning in distance education. Open Learning, 25(3), 251-257.

Sey, A. (2007). Mobile phone systems in Africa: Developments, uses and implications. Paper presented at the 93rd National Communication Association Annual Convention. Chicago, USA.

Song, S. (2005). Viewpoint: Bandwidth can bring African universities up to speed. Retrieved on 23 September 2010 from http://www.scienceinafrica.co.za/2005/september/ bandwidth.htm

Van Dijk, J. (1999). The network society. London: Sage.

Van Audenhove, L. (2003). Theories on the information society and development: recent theoretical contributions and their relevance for the developing world. Communication, 29(1\&2), 48-67.

Webster, F. (2006). Theories of the information society (3rd ed.). London: Routledge.

Correspondence: Elirea Bornman, Professor, Department of Communication Science, University of South Africa, Pretoria, South Africa 